\title{
ISOLAMENTO DE SALM ONELLA : COMPARAÇÃO DAS ETAPAS DE PRÉ- ENRIQUECIMENTO E ENRIQUECIMENTO DIRETO DE AMOSTRAS DE FEZES ARMAZENADAS POR 24E 96 HORAS
}

\section{J.B. de Paiva' ${ }^{1 *}$, E.V . Sterzo' ${ }^{1}$ S.A . Ribeiro², E.A . Pereira ${ }^{1}$, A . Berchieri Junior ${ }^{1}$}

'Universidade Estadual de São Paulo, Faculdade de Ciências Agrárias e Veterinárias, Departamento de Patologia Veterinária, Via de acesso Paulo Donato Castellane, s/ no, CEP 14870-000, Jaboti cabal, SP, Brasil. Email: jackboldrin@hotmail.com

\section{RESUMO}

Este trabal ho foi desenvolvido para avaliar comparativamente o isolamento de Salmonella sorotipos Enteritidis (SE) e Typhimurium (STM) a partir do enriquecimento direto (ED) ou processamento com pré-enriquecimento (PE) deamostras defezes deaves adultas, armazenadas em água peptonada tamponada a 1\% (APT) por 24 ou $96 \mathrm{~h}$ a $44^{\circ} \mathrm{C}$. Utilizou-se os caldos de enriquecimento Rapapport-Vassiliadisnovobiocina(RVN), tetrationato-novobiocina(TN )eselenitonovobiocina (SN) e os mei os para plaqueamento ágar verdebrilhante(VB), ágar deMacConkey (MC), ágar deH ektoen (HE), ágarSal monella-Shigella (SS), ágar xiloselisinadesoxicolato (XLD) eágar xiloselisinatergitol 4(XLT4). O procedimento bacteriológicoinduiu as etapas depréenriquecimento, enriquecimentoem cal do seletivo, plaqueamento, testesbioquímicospresuntivoseconfirmação sorológica comutilização desoros polivalentesanti-antígenos somáticoseanti-antígenosflagelares de Salmonella. Não houve diferença estatisticamente significativa $(p>0,05)$ para as amostras armazenadas por 24h submetidastanto ao PE quanto ao ED. Entretanto, emarmazenagem por $96 \mathrm{~h}$ o número de isolamentos nas amostras submeti das ao $\mathrm{PE}$ foi estatisticamentesuperior às submetidasao $E D(p<0,05)$. Quantoaoscaldos enriquecedores, não houvediferença estatísticadenúmero de isolamentos $(p>0,05)$ entre os cal dos SN eTN , mas o cal do RVN mostrou-seestatisticamente superior aos demais $(p<0,05)$. Para os meios de plaqueamento, o XLD destacou-se por promover maior número de recuperações, embora sem significado estatístico $(p>0,05)$ para as amostras estocadas por 24h. Entreos doissorotipos deSal monella(SE eSTM) não houvediferençaestatística no número de recuperações $(p>0,05)$.

PALAVRAS-CHAVE: Fezes de aves, enriquecimento sel etivo, comparação de meios, procedimento bacteriológico.

\begin{abstract}
ISOLATION OF SALM ONELLA FROM POULTRY FECES: A COMPARISON OF PREENRICHIMENT AND DIRECT ENRICHMENT. This work was carried out to assess the pre enrichment (PE) and enrichment (DE) steps for isolating Salmonella serotypes Enteritidis (SE) and Typhimurium (STM ) from chicken feces kept at $4^{\circ} \mathrm{C}$ for 24 and $96 \mathrm{~h}$. The samples wereartificially contaminated and kept in $1 \%$ peptone water at $4^{\circ} \mathrm{C}$ for 24 or $96 \mathrm{~h}$. After that, part of them was incubated at $37^{\circ} \mathrm{C} / 24 \mathrm{~h}$ and part was inoculated into enrichment broth, selenite broth plus novobiocin (SN) and tetrathionate broth plus novobiocin (TN) incubated at $37^{\circ} \mathrm{C} / 24 \mathrm{~h}$. The PE culture was inoculated in SN, TN and Rapapport-Vassiliadis novobiocin (RVN), al so incubated at $37^{\circ} \mathrm{C} / 24 \mathrm{~h}$. The enrichment broth was plated on brilliant green agar (BGA), MacConkey agar (MCA), Hektoen agar (HEA), Sal monella-Shigella agar (SSA), xylose-lysine desoxicholate agar (XLDA) and xylose-lysinetergitol $4(X L T 4)$, which were incubated at $37^{\circ} \mathrm{C} / 24 \mathrm{~h}$. Sal monella-like colonies weresubmitted to TSI agar and LIA agar, and incubated at $37^{\circ} \mathrm{C} / 24 \mathrm{~h}$, as well as to slide agglutination tested with poly $\mathrm{O}$ and poly $\mathrm{H}$ Sal monella antiserum. When the samples werestored for 24h therewasno differencebetween PE and DE $(p>0.05)$. However after 96h thePE wassuperior to $D E(p<0.05)$. For enrichment, better results wereseen with RVN broth $(p<0.05)$. TheXLD yielded
\end{abstract}

\footnotetext{
2Lanagro, Campinas, SP, Brasil.
}

*BolsistalC Fapesp 
morepositiveresults although with no statistical significance. Therewas no statistical difference between serotypes SE and STM isolation.

KEY WORDS: Salmonella isolation, chicken feces, pre-enrichment, enrichment.

\section{INTRODUÇÃO}

O intenso crescimento edesenvolvimentodo setor avícola, nas últimas décadas, tornou-o rentável, produtivoecompetitivo. Contudo, osistemaintensivo de criação eabateprecocedefrangos, favorecea presença deSalmonella noproduto final (BERCHIERIJUNIor etal., 1987; BerCHIERI JunIOR et al., 1989). Entre os mais de 2.500 sorotipos deSalmonella, al guns podem infectar as aves causando ou não o paratifo aviário e, através de produtos al imentícios de origem avícola, estarem envolvidos em toxinfecções alimentares em seres humanos (BERCHIERI JUNIOR, 2000; VAN IM m ERSEEL et al. 2005). Segundo BARRow (2000), as salmonelas continuam sendo a maior causa de toxinfecção al imentar humana, e devido a sua habilidade de colonizar o trato entérico dasgal inhas, aumenta o risco decontaminação dacarcaçaedeovos. N adécadade80, houve um aumento expressivo nos casos de toxinfecções alimentares associadas a salmonelas na Europa, A mérica do Nortee do Sul (Rodrigue et al., 1990), fato que culminou com a intensificação de pesquisas sobre salmoneloses em animais e seres humanos (BARRow, 1993). No Brasil também houve um significativo aumento nos casos de contami nação dehumanos, destacando-se a Salmonella Enteritidis entre os sorotipos mais isolados Fernandes et al., 2003; TAVECHIO etal., 1996) tambémemaves (BERCHIERIJUNIOR, 2000; KANASHIRO, 2005).

Tendo-se em vista a participação de aves no contágio dehumanos, foi criado o Programa Nacional de SanidadeA vícola(PNSA) peloMinistériodaAgricultura(Portariano193), comadoção denormas (Portaria no8) paraprevenirecontrolar a presençadeSal monella em aves (BrasIL, 1994; BrasIL, 1995).

A s etapas necessárias para o isolamento eidentificação de espécimes do gênero Salmonella seguem uma seqüência queinclui as etapas depré-enriquecimento, enriquecimento direto (seletivo), plaqueamento em meios semi-sólidos, análise bioquímica e tipificação sorológica (LITCHFIELD, 1973). O enriquecimento e o plaqueamento são as etapas com maior número de possibilidades de meios de cultivos (Flowers et al., 1992; Wray \& Davies, 1994; Waltman $\&$ MaLLINSON, 1995), pois estes devem auxiliar no desenvolvimentoerecuperação dabactériaao mesmo tempo em que devem impedir o desenvolvimento de microrganismos competidores. A falta deresultados conclusivospropiciaampla discussão ereformulação de meios consagrados, assim como surgimento de novos produtos.
O pré-enriquecimento (PE) éutilizado para análisedematerial desidratado parafavorecer a recuperação deorganismos deprimidosou danificados. Dessa forma, a incubação inicial das amostras em meio não sel etivo (PE) permitea recuperação de células debilitadas antes de sua inoculação em meios sel etivos. A maioriadosprotocolosindicaqueotempomínimode incubação em meios de PE deveser de 16 horas a 370 C (D' Aoust \& Maishment, 1997; Mohr et al., 1974). A pós a incubação, via de regra, $1 \mathrm{~mL}$ do caldo pré enriquecedor étransferido para $10 \mathrm{~mL}$ decal do seletivo, com exceção do caldo Rappaport-Vassilidis, para o qual deve-se transferir $0,1 \mathrm{~mL}$ em $10 \mathrm{~mL}$ do caldo.

TATE et al. (1990) compararam o isolamento de Salmonella com esem o PE em amostras deambientes de granjas. Com enriquecimento direto em caldo tetrationato, $73 \%$ das amostras foram positivas para Sal monella, enquanto $77 \%$ das amostras foram positivas quando o PE era empregado antes do enriquecimento em cal do tetrationato.

WaLtMAn (1998), cita 3 famílias de meios de enriquecimento seletivo: caldo selenito (EN), caldo tetrationato(TN ) ecal do Rapapport-Vassiliadis(RV), acrescidos ou não denovobiocina. Segundo PESSOA \& Реіхото (1971) a adição de novobiocina ao caldo selenito favorece o isolamento de Salmonella em ao maior número de tentativas para uma amostra.

$O$ caldo de enriquecimento RV éum meio de alta seletividade, razão pelaqual seu emprego érestrito a amostrassubmetidasprimeiramenteao PE. Estemeio foi inicialmente formulado para isolamento de Sal monella em fezes, mas estudos posteriores atestaram sua eficiência para isolar Salmonella a partir de outros tipos de materiais.

Assim como para os caldos de enriquecimento seletivo, diversas sugestões de conteúdo são feitas para os mei os semi-sólidos. A lguns trabal hos ressalvam quenão épossível estabelecer qual seria o meio deplaqueamento ideal (MCCARTH, 1966; SHERROD et al., 1995; Y uno et al ., 1995; Petersen, 1997). Cox et al . (1972) e N ASCIMENTO et al. (2000) indicaram o uso do ágar verde brilhante(VB) para o isolamento deSalmonella de fezes de aves ealimentos de origem avícola. $H u \&$ GıBBS (1995) evidenciaram a eficiência do ágar VB para o isolamento deSal monella emamostras defezes. Destacou-se o uso do ágar xilose-lisina desoxicolato (XLD) paraisolamento deSal monell a a partir deamostras decarne(ReISSBRodt etal., 1996; A LVEIKE\& SKEJERVE, 2000) e em fezes (Hu \& GIBBS, 1995). ReISSBRODT et al, (1996), Wiberg \& Norberg (1996), Hara-Kudo et al., 
(2001) indicam o uso do ágar xilose-lisina tergitol 4 (XLT4) parao isolamento deSalmonella defezes, segundo MILLER et al. (1991) e MilLer et al. (1994) este meio é exclusivo para Salmonella, conseguindo evitar a presença de competidores, especial mente P roteus sp.

Da mesma formaque para os cal dos deenriquecimento seletivo, mel hores resultadosadvém dacombinação de dois ou mais meios de plaqueamento, (Fernandes etal., 2003; TAYLOR \&SILliker 1961; BerChIERI JUNIOR. et al., 1986; N ASCIMENTo et al., 2000).

Geralmente, apesquisa deSal monella emamostras defezes, inicia-sepelo enriquecimento seletivo ou até mesmo pelo plaqueamento direto em ágar seletivo. Contudo, o exame de amostras col hidas em granjas, nemsemprepodeser realizado em $24 \mathrm{~h}$. A ssimsendo, o presentetrabal ho propõe-sea investigar o efeito da armazenagem de amostras de fezes de aves adultas, contaminadas experimentalmente com Salmonella Enteritidis eSalmon el la Typhimurium, conservadasa 4ㅇ C em água peptonada tamponada a $1 \%$ (A PT) por 24e96h elevadasaprocesso deenriquecimento direto em caldos seletivos comparativamente com o processamento a partir do pré-enriquecimento em APT, conforme estabelece o PNSA (BRASIL, 1995). O enriquecimento foi realizado com os cal dos selenitonovobiocina (SN), tetrationato-novobiocina (TN) e Rapapport-Vassiliadis-novobiocina (RVN) e o plaqueamento, com meios de ágar verde brilhante (VB), MacConkey (MC), Hektoen (HE), SalmonellaShigella (SS), ágar xiloselisina desoxycolato (XLD) e xiloselisina tergitol 4(XLT4).

\section{MATERIAL E MÉTODOS}

\section{Preparo das amostras experimental mente con- taminadas por Salmonella}

Para arealização do trabal ho, utilizou-sefezes de aves adultas do aviário da FCA V-Unesp,J aboticabal, SP, edeumagranjacomercial local izada naregião de Campinas, SP. AsfezesprovenientesdaFCA V-Unesp foram processadas no laboratório de Ornitopalogia daFCA V-Unesp, Jaboticabal, SP e da região deCampinaspeloLAN AGRO - Campinas-SP, setor aviárias. Asfezesforam contaminadasexperimentalmentecom cepas de Salmonella, sorotipos Enteritidis e Typhimurium.

Asculturasforam preparadasem cal do nutriente, com incubação a 37으/ 24h sob agitação constante. A seguir, procedeu-sea contagem decélulas viáveis de Salmonella, diluindo-as decimal menteemPBSpH 7,4. De cada diluição, transferiu-se $0,1 \mathrm{~mL}$ para placas contendo ágar verde brilhante, queforam incubadas a37- $\mathrm{C} / 24 \mathrm{~h}$, obtendo-seonúmero deunidadesformadoras decolônia por mL.Combasenestesresultados, utilizou-se $2 \mathrm{~mL}$ daculturadiluída em cal do nutriente, contendo $1,1 \times 10^{5} \mathrm{UFC} / \mathrm{mL}$, que foram adicionadosa20 g defezes ( $1,1 \times 10^{4} \mathrm{UFC} / \mathrm{g}$ defezes). Ostestes paracadasorotipo foram realizados separadamente.

A colheita das amostras experimental mentecontaminadas foi realizada com 30 suabes de al godão estéreis, queforam passadosnasfezesecolocados, em grupos de 5 unidades, em frascos contendo água peptonada tamponada a 1\% (APT), atuando como meio detransporte. Trêsfrascosforamacondionados a $4^{\circ} \mathrm{C}$ por $24 \mathrm{~h}$, e os outros três por $96 \mathrm{~h}$. Este procedimento foi repetido 2 vezes para cada sorotipo.

\section{Procedimento microbiológico}

De cada período de armazenagem, uma amostra foi préenriquecida em APT eincubada a $370 \mathrm{C} / 24 \mathrm{~h}$. As outras duas foram diretamente enriquecidas em caldo selenito-novobiocina (SN) e em caldo tetrationato-novobiocina (TN), queforam incubados a 37으 $/ 24$ h. O préenriquecimento eo enriquecimento direto foramrealizadosrespeitando aproporção de 1:10. Do crescimento em APT, transferiu-se $1 \mathrm{~mL}$ para $10 \mathrm{~mL}$ decal doSN , $1 \mathrm{~mL}$ para $10 \mathrm{~mL}$ decaldoTN e0,1 $\mathrm{mL}$ para $10 \mathrm{~mL}$ de caldo Rappaport Vassiliadis N ovobiocina (RVN), que foram incubados a $37^{\circ} \mathrm{C} /$ 24h. A partir dos caldos de enriquecimento, foram semeadas placas contendo os meios ágar verde briIhante, ágar de MacConkey, Hektoen, SalmonellaShigella, ágar Xilose Lisina Desoxicolato (XLD) e Xilose Lisina Tergitol-4 (XLT-4). As placas foram incubadas a $37^{\circ} \mathrm{C} / 24 \mathrm{~h}$. A confirmação daSalmon ella foi realizada submetendo-se as colônias suspeitas a testes bioquímicos em tubos contendo ágar tríplice açúcar ferroinclinado (TSI) eágar lisinaferroinclinado (LIA), que foram incubados a $37^{\circ} \mathrm{C} / 24 \mathrm{~h}$. Confirmando-se a suspeita do gênero, as colônias foram submetidasaotesterápido deaglutinação emlâmina, com soro polival enteanti-antígeno somático $\mathrm{O}$ esoro polivalente anti antígeno flagelar $\mathrm{H}$ deSalmonella.

\section{A nálise de Resultados}

Para análise estatística dos dados utilizou-se o testenão paramétrico Qui-Quadrado ( $\left.X^{2}\right)$ (THRUSFIELD, 1995).

\section{RESULTADOS}

$\mathrm{Na}$ Tabela 1 estão dispostos os resultados do isolamento deSalmonella a partir dos caldos deenriquecimento utilizados, considerando-se o pré-enriquecimento (PE) e o enriquecimento direto (ED) das amostrasarmazenadaspor 24e96h. Das 25amostras armazenadas por 24h obteve-se isolamento em 13 
delas com o ED contra 19 no processamento que utilizou PE. Estes dadosnãodiferemestatisticamente entresi $(p>0,05)$. Para as amostras armazenadas por $96 \mathrm{~h}$, das 25 amostras anal isadas obteve-seisolamento positivo em 21 delas quando submetidas ao PE anteriormente ao enriquecimento, contra 11 no ED, diferença estatisticamente significativa $(p<0,05)$.

$\mathrm{N}$ as amostras submetidas ao ED e armazenadas por 24e96h, o número deisolamentos no caldo TN e no caldoSN não diferiram estatisticamenteentresi ( $p$ $>0,05$ ) e, ainda, não seobservou diferença estatisticamente significativa quando se comparou os resultadosdaassociação decaldoscomo uso do caldoTN ou do caldo SN isolados.

$\mathrm{N}$ asamostras submetidasao $\mathrm{PE}$ armazenadaspor 24 e 96h, houve superioridade no número de isolamentos das amostras enriquecidas em caldo RVN quando comparadas aos caldos TN eSN $(p<0,05)$. Também se observou diferença estatisticamente sig- nificativa $(p<0,05)$ ao se comparar os resultados da associação dos cal dos com o uso do cal do SN ecaldo TN isoladamente. A análise da associação decaldos comousoisolado docaldoRVN não mostrou diferença estatisticamente significativa ( $p>0,05)$.

A Tabela 2 exibe os resultados referentes ao isolamento deSal monella emfezes deaves, segundo osmeios de plaqueamento utilizados. Para as amostras processadasapós24h deestocagem, osresultadosapresentados não diferem estatisticamente entre si $(p>0,05)$. Notou-sesuperioridadenuméricadoságaresXLD eSS em relação aos demais. Para as amostras processadas após 96horasdeestocagem, oágar XLD apresentou-se estatisticamentesuperior aos demais $(p<0,05)$.

A Tabela 3 exibeas comparações entreo número deisolamentos deSalmon ella Enteritidis eSalmonella Typhimurium. Não houvediferençaestatisticamente significativa $(p>0,05)$ entreo número total de isolamentos dos dois sorotipos.

Tabela 1 - Isolamento de Salmonella defezes deaves adultas contami nadas experimentalmente, considerando-seo préenriquecimento (PE) eo enriquecimento direto(ED) deamostras conservadasemágua peptonadatamponada(APT) por 24 e $96 \mathrm{~h}$ a $4^{\circ} \mathrm{C}$.

\begin{tabular}{|c|c|c|c|c|c|c|c|}
\hline \multirow[b]{3}{*}{ PE } & \multirow[b]{3}{*}{ Enriquecimento } & \multicolumn{6}{|c|}{$\mathrm{N} \cong$ de amostras armazenadas } \\
\hline & & \multicolumn{3}{|c|}{24 horas } & \multicolumn{3}{|c|}{96 horas } \\
\hline & & Positivas & $\%$ & Total & Positivas & $\%$ & Total \\
\hline$\overline{\mathrm{APT}}$ & SN & 5 & 20 & 25 & 6 & 24 & 25 \\
\hline APT & TN & 9 & 36 & 25 & 6 & 24 & 25 \\
\hline \multirow[t]{3}{*}{ APT } & RVN & 17 & 68 & 25 & 18 & 72 & 25 \\
\hline & SN & 8 & 32 & 25 & 7 & 28 & 25 \\
\hline & TN & 11 & 44 & 25 & 11 & 44 & 25 \\
\hline \multirow[t]{2}{*}{ APT } & SN,TN, RVN & 19 & 76 & 25 & 21 & 84 & 25 \\
\hline & SN,TN & 13 & 52 & 25 & 11 & 44 & 25 \\
\hline
\end{tabular}

SN : cal do selenito-novobiocina, TN : cal do tetrationato-novobiocina, RVN , caldo rapapport-vasiliadis-novobiocina.

Tabela 2-I solamento deSalmonella defezes deaves adultas contaminadas experimentalmente, considerando-seosmeios para plaqueamento das amostras conservadas em água peptonada tamponada (APT) por 24 e $96 \mathrm{~h}$ a $4^{\circ} \mathrm{C}$.

Meiospara № de amostras armazenadas

plaqueamento emágar

№ de amostras armazenadas

\begin{tabular}{lcccrcc} 
& \multicolumn{3}{c}{ 24 horas } & \multicolumn{3}{c}{96 horas } \\
\cline { 2 - 7 } & Positivas & $\%$ & Total & Positivas & $\%$ & Total \\
\hline VB & 11 & 44 & 25 & 19 & 76 & 25 \\
MC & 11 & 44 & 25 & 8 & 32 & 25 \\
HE & 5 & 33 & 15 & 8 & 53 & 15 \\
SS & 6 & 60 & 10 & 7 & 70 & 10 \\
XLD & 7 & 70 & 10 & 9 & 90 & 10 \\
XLT4 & 8 & 53 & 15 & 7 & 46 & 15 \\
\hline
\end{tabular}

VB: ágar verde brilhante, MC: MacConkey, HE: Hektoen, SS: Salmonella-Shigella, XLD: xilose, lisina desoxicolato, XLT4: xiloselisinatergitol 4. 
Tabela3-Isolamento deSalmonellaEnteritidis(SE) eSalmonellaThyphimurium(STM) defezes deavesadultascontaminadas experimental mente, considerando-seo pré-enriquecimento (PE) eoenriquecimento direto (ED) deamostrasconservadas em água peptonada tamponada (APT) por 24 e $96 \mathrm{~h}$ a $4^{\circ} \mathrm{C}$.

\begin{tabular}{llrrrrrr}
\hline Início sequência & Serovar & \multicolumn{5}{c}{ № de amostras armazenadas } \\
\cline { 3 - 8 } & & \multicolumn{5}{c}{24 horas } & \multicolumn{5}{c}{96 horas } \\
\cline { 2 - 8 } & & Positivas & $\%$ & Total & Positivas & $\%$ & Total \\
\hline PE & SE & 14 & 70 & 20 & 16 & 80 & 20 \\
PE & STM & 5 & 100 & 5 & 5 & 100 & 5 \\
ED & SE & 8 & 66 & 20 & 6 & 30 & 20 \\
ED & STM & 5 & 100 & 5 & 5 & 100 & 5 \\
PE+ED & SE & 14 & 70 & 20 & 19 & 95 & 20 \\
PE+ED & STM & 5 & 100 & 5 & 5 & 100 & 5 \\
\hline
\end{tabular}

\section{DISCUSSÃO}

Osdados referentesao isolamento deSalmonellaem fezes de aves armazenadas por 24h não mostraram diferença $(p>0,05)$ entreas etapas deED ePE, embora hajasuperioridadenumérica deisolamento nasamostrassubmetidasao PE. Paraasamostrasarmazenadas por 96h, osvaloresobtidosdiferiramentresi $(p<0,05)$, sendo o número de isolamentos superior quando o procedimento iniciou-se com o PE. Comparando-se o número de isolamentos positivos entre 24 e $96 h$, estes não diferiram entre si $(p<0,05)$ quando as amostras armazenadas por $96 \mathrm{~h}$ foramsubmetidasàetapadePE. Estes dados assemel ham-seaos observados por TATE et al. (1990), que obtiveram $73 \%$ de isolamento com amostrassubmetidasao ED contra 77\%depositividade paraassubmetidasaoPE, com $75 \%$ deisolamentossem estocagem dasamostrase $86 \%$ deisolamentosquando as amostras foram armazenadas.

Os valores relativos ao desempenho dos caldos enriquecedores SN e TN para o isolamento de Salmonella defezes mostrou que os desempenhos individuais foram muito próximos, não apresentando diferençaestatistica $(p>0,05)$. Estes resultados corroboram com aqueles descritos por TAYLOR \& SILLIKER (1961), HUHTANEN \& N AGSKI (1972) eN OGUEIRA \& FrANco (1995) osquaistambémnão encontraram diferença estatísticaentreosisolamentosobtidoscomoscaldos. Sendo assim, não são condizentes aos resultados apresentados por FoRWARD \& RAINNIE (1997) eA LSEIKE $\&$ SKJERVE (2000) que consideraram o caldo selenito comrendimentosuperiornarecuperaçãodeSalmonella a partir defezes. Quanto ao cal do RVN, estemostrouse superior aos demais $(p<0,05)$, provavelmentepor se tratar de um meio de alta seletividade com uso restrito a amostras submetidas ao PE.

Conforme relatos anteriores (TAYLOR \& SLLIKER 1961; BeRCHIERI JUNIOR et al., 1986; WALTMAN, 1998; SMYSER \& SNOYENBOS, 1969; FERnANDES et al ., 2003; N ASCIMENTO et al., 2000), também foi evidente nestetraba-
Iho, que os melhores resultados advém da combinação de caldos.

A análise dos resultados relativos aos meios de plaqueamento possibilitou evidenciar nas amostras armazenadas por $24 \mathrm{~h}$, asuperioridadenuméricasem significado estatístico do ágar XLD e do ágar SS, os quais permitiram o isolamento positivo em $70 \%$ e $60 \%$, das amostras, respectivamente, à semel hança dos resultados encontrados por N Ascimento et al. (2000). Para as amostras armazenadas por 96 horas a superioridade do ágar XLD em relação aos demais foi estatisticamentesignificativa $(p<0,05)$. Damesma forma que para os caldos de enriquecimento, a utilização de vários meios de plaqueamento permitiu maior número deisolamentos, por aumentar a possibilidade de recuperação.

$N$ ão houve diferença estatísticamente significativa $(p>0,05)$ entre a recuperação dos sorotipos $(S$. Enteritidis e S. Typhimurium) concordando com Arroyo \& Arroro (1995), os quais afirmam que o isolamento deSal monella independedo sorotipo inoculado e do meio utilizado, e que este depende da concentração deSal monella na amostra eda competição desta com outras bactérias.

Os resultados deste trabal ho demonstram que a etapa de pré-enriquecimento de amostras de fezes estocadas por $96 \mathrm{~h}$ favorecem o isolamento de Salmonella. Permitemainda, vislumbrar adificuldade em se definir qual o mel hor cal do deenriquecimento e meio de plaqueamento para o isolamento de Salmonella, reforçando dessa forma a idéia de que o melhor a se proceder éa associação de dois ou mais caldos deenriquecimento e meios de plaqueamento.

\section{AGRADECIMENTOS}

Ao Sr. Antônio José dos Santos e Sra. A parecida Rodrigues Baptista pelo auxílio técnico laboratorial e aoCN PqeFAPESP peloapoiofinanceiroebolsasdelC. 
ReferênCIAS

Albuquerque, R.; Ito, N.M.K.; MiyajI, C.I. Estudo comparativo dediferentesmeiosdeculturaparao isolamento desal monelas em matérias-primaserações. Brazilian J ournal of V eterinary R esearch and A nimal Science, v.37, n.1, 2000.

A LSEIKE, O. \& SKEJERVE, E. Probability of detection ofSalmonella using differentanalytical procedureswithemphasison subespeciesdiarizoneserovar 61:k: 1,5(7). International Journal of Food M icrobiology, v.58, p.49-58, 2000.

US. EPA.SewageSludgeRegulationsPart503-Standard for the use or disposal of sewage sludge. USEPA, 1992.

ARroYo, G.; ARROYO, J.A. Efficiency of different enrichment and isolation proceduresfor thedetection of Salmonella serotypos in edible offal.J ournal of A pplied Bacteriology, v.79, n.4, p.360-367, 1995

Barrow, P.A. Salmonella-present, past and future. A vian Pathology, v.22, p. 651-659, 1993.

Barrow, P.A. The paratyphoid Salmonellae. Review Science Technology, v.19, p.351-375, 2000.

Berchieri Junior, A.; I rino, K. Paulillo; N eme, S.N.;Paulillo, A.C.; Calzada, C.T.; Fernandes, S.A.; Pessoa, G.V.A. Contaminação por Salmonella em farinha de origem animal utilizadas no preparo de rações. Pesquisa V eterinária Brasileira, v.4, p.83-88, 1984.

Berchieri Junior, A.; kino, K. Paulillo, A.C.; Neme, S.N.; Fernandes, S.A.;KRonKa, S.N.;P essoA, G.V.A.Eficáciados caldosselenito-novobiocinaetetrationato-novobiocina napesquisa deSalmonella emfarinha decarne.Pesquisa V eterinária Brasileira, v.6, p.133-136, 1986.

Berchieri Junior, A.; Paulillo, A.C.; Rossi Jr, O.D.; Irino, K. Fernandes, S.A; Ávila, F.A.; Pessoa, G.V.A.; Cazada, C.T. Salmonella em abatedouro avícola. A rs $V$ eterinária, v.3, p.81-87, 1987.

Berchieri Junior, A.; Adachi, S.Y.; Calzada, C.T.; Paulillo, A.C.; SCHOKen-IturRino,R.P.;T AVECHIO, A.T.Farinhade carne como fonte de Salmonella em granja avícola. Pesquisa V eterinária Brasileira, v.9, p.9-12, 1989.

Berchieri Junor, A. Enfermidade das aves. In: Berchieri Junior, A. \& MACARI, M. D oenças das aves. Campinas: FACTA, 2000. p.183-253.

Blivet, D.; Salvat, G.; Humbert, F. Colin, P. Evaluation of a new enrichment broth for isolation of Salmonellaspp from poultry products. International Journal of Food M icrobiology, v.38, p.211-216, 1997.

BrASIL. M inistério daA gricultura, PecuáriaeA bastecimento. Programa N acional de Sanidade avícola: A tos Legais. Portaria no 193 de 19 de setembro de 1994: Institui o Programa $\mathrm{N}$ acional deSanidade A vícola, no âmbito daDAS e cria o Comitê Consultivo do Programa de SanidadeA vícola. Brasília, 1994. p.2-3

BRASIL. Ministério daAgricultura, PecuáriaeA bastecimento. Programa N acional de Sanidade avícola: A tos Legais. Portaria no 8 de 23 de janeiro de 1995: Estabelece o Método A nalítico de Carcaças de aves e Pesquisa de Salmonella. Brasília, 1995. p.60.

CARRINGTON, E.G. Theisol ation and identification of Salmonellaspp. in sewagesludges: acomparasion of methods andrecommen dations for a standard technique. Cambridge: Water Resources Centre, 1980. (Technical Report, TR 129).
Cox,N.A.;D avis,B.H.,K endall,J.H.,W atts,A.B.,Colmer,A.R. Salmonella in thelaying hens. A comparison of various enrichmentbrothsand plating mediafortheisolation of Salmonellafrompoultry fecesand poultryfood products. Poultry Science, v.51, n.4, p.1312-1316, 1972.

D'Aoust, J.Y. \& MaISHMEnT, C. Preenrichment conditions for effective recovery of Salmonella in foods and feed ingredients. Journal of F ood Protection , v.42, p.153-157, 1997.

Fernandes, S.A; Ghiliardi, A.C.; Tavechio, A.T.; Machado, A.M; Pgnatari, A.C. Phenotypic and molecular characterization of SalmonellaEnteritidisstrainsisolated en São Paulo, Brazil. Revista do Instituto de M edicina Tropical de São Paulo, v.45, n.2, p.54-63, 2003.

Flowers, R.S.; D' Aoust, J.Y.; Andrews, W.H.; Bailey, J.S. Salmonella. In: A merican Public Health Association. Compendium of methods for themicrobiol ogical examination of foods. 3.ed. Washington: APHA, 1992. p.371-421.

ForWARD, K.R. \& RaINNIE, B.J. Use of sel enite enrichment broth for the detection of Salmonella from stool: a report of one year experience at a provincial public health laboratory. Diagnostic M icrobiology Infection D iseases, v.29, p.215-217, 1997.

Hara-Kudo, Y.; Kumagal, S.; Masuda, T.; Goto, K.; OhtSUda, K.; MASAKI, H.; TANAKa, H.; TANno, K.; MiYahara, M.; KonUma, H. Detection osSal monella Enteritidisin shell and liquid eggs using enrichment and plating. International Journal of Food M icrobiology, v.64, p.395399, 2001.

HNSON, R.A.I Improved sel ectiveprocedurefor detection of Salmonel la from poultry and sausageproducts.J ournal Food Protect, v.51, p.391-396, 1998.

$\mathrm{H} \cup, J . C . \& \mathrm{G}$ IBBS, R.A.A comparison of culturemethodsfor the detection of Salmonella in wasterwater sludge. Science and Technology, v.31, p.303-306, 1995.

HuhtANEN, C.N.\& NAGHSKI,J. Effect of typeof enrichment and duration of incubation on Salmonella recovery from meat-and-bone meal. A pplied M icrobiology, v.23, p.578-85, 1972.

KANASHIRO, A.M.I.Serovars of Salmonellaspp.I solated from broiler chickensand commercial breedersin diverse regions in Brazil from July 1997 to December 2004. Brazilian Journal Poultry Science, p.195-197, 2005.

LITCHFIELD, J.H. Sal monella and thefood industry: methods for isolation, identification and enumeration. Critical Reviews in Food Technology, v.3, p.415-456, 1973.

MCCARTHY, M.D. The use of XLD agar as a medium for isolation of intestinal pathogens. $N$ ew Z ealand J ournal M edicineLaboratory Technologyc, v.20, p.344-349, 1966.

Miller, R.G.; Tate, C.R.; Mallinson, E.T.; Shererer, J.A. Xylose-Lisine-Tergitol 4: an improved agar medium for the isolation of Salmonella. Poultry Science, v.70, p.2429-2432, 1991.

Miller, R.G.; TAte, C.R.; Mallinson, E.T. Improved XLT4 agar: small addition of peptone to the promote stronger production of hydrogen-sulfidebySalmonella. Journal of Food Protection, v.57, p.854-858, 1994.

Mohr, H.K; TREnK H.L.; Yeterian, M. Comparison of fluorescent-antibody methods and enrichment serology for detection of Salmonella. Applied M icrobiology, v.20, p.273-275, 1974. 
Nascimento, M.S.;B erchieri Junior,A.;Barbosa, M.D.;Zancan, F.T.; Almeida, W.A.F. Comparison of different enrichment broth and plating mediaused to isolation Salmonella from chicken carcasses and poultry faeces samples. Brazilian J ournal of Poultry Science, v.2, p.8591, 2000.

Nogueira, B.T.C.P. \& Franco, B.D.G.M. Recovery of acid Salmonellaefromartificially contaminated mayonnaise. R evista de M icrobiologia, v.26, p. 28-31, 1995.

PessoA, G.V.A. \& Peixoto, E.s. Caldo selenito-novobiocina um meio demaior seletividadeparao isolamento de Salmonella defezes. Revista do I nstituto A dol fo Lutz, v.31, p.1-3, 1971.

Petersen, L. A comparison of EF-18and modified brilliant green agar with lutensit for isolation Salmonellafrom poultry samples. A cta V eterinaria Scandinavica, v.38, p.79-85, 1997.

Reissbrodt, R.; V ielitz, E.; K ormann, E.; R absch, W.; K Uhn, $H$. Ferrioxamine E-supplemented pre-enrichment and enrichmentmediaimprovevariousisolation methods for Salmonella. International J ournal of F ood M icrobiology, v.29, p.81-91, 1996.

RodrIGUe, D.C.;T AUXE, R.V.; R owe, B. International increase in SalmonellaEnteritidisphagetypt4: anew pandemic? Epidemiology and Infection, v.105, p.21-27, 1990.

Sherrod, P.S.; A maguana, R.M.; Andrews, W.H.;June, G.A.; HAMMACK, T.S. Relative effectiveness of selective plating agars for recovery of Salmonella sp. from selected high-moisture foods. Journal of AOAC International, v.78, p.670-690, 1995.

Smyser, C.F. \& Suoyenbos, G.H. Evaluation of several methods of isolating Salmonellae from poultry litter and animal feedstuffs. A vian D iseases, v.13, n.1, p.133141, 1969.

Smyser, C.F. \& Sioyenbos, G.H. Enrichment serology compared with adirect-cultureprocedurefor isolating Salmonella from rendered animal by-products. A vian D iseases, v.15, p.581-587, 1971.

Tate, C.R.; Miller, R.G.; Mallinson, E.T.; Douglass, L.W. JOHNSTON, R.W.Theisolation of Salmonellafrom poultry environmental samples by several enrichment procedures using plating media with and without novobiocin. Poultry Science, v.69, n.5, p.721-726, 1990.
Tavechio, A.T.; Fernandes, S.A.; Neves, B.C.; Dias, A.M.; IRINO, K. Changing patterns of Salmonella serovars: increase of Salmonella Enteritidisin São Paulo, Brazil. Revista do Instituto de M edicina Tropical de São Paulo, v.38, n.5, p. 315-322, 1996.

TAYLOR, W.I. \& SILLIKER, J.H. Isolation of Salmonella from samples IV. Comparison of methods of enrichment. A pplied M icrobiology, v.9, p.484-486, 1961.

ThruSFIELD, M.Veterinary Epidemiology . Cambridge:Blakweel Science, 1995. p.479.

Van Immeersel, F.; M ethner,U.;R Ychlik, L.; N agy, B.; V elge, P.; Martin, G.; Foster, N.; Ducatelle, R.; Barrow, P.A. Vaccination and early protection against non-hostspecific Sal monella serotypes en poultry: exploitation of innateimmunity and microbial activity.Epidemioogy and Infection, p.1-20, 2005.

WaLtMAN, W.D.; Mallinson E.T. Isolation of Salmonella from poultry tissue and enviromental samples: a nationwide survey. A vian D iseases, v.39, p.45-54, 1995.

WALTMAN, W.D. Isolation of Salmonella from poultry environments. In: INTERNATIONAL SYMPOSIUM ON FOOD-BORNE SALMONELLA IN POULTRY, 1998, Baltimore, 1998, p.133-153.

Wilberg, C. \&; Norberg, G.P. Comparasion between a cultural procedureusing Rappaport-Vassiliadisbroth and motility enrichments on modified semisolid Rappaport-Vassiliadis mediumfor Salmonella detection from food and feed. Journal Food M icrobiology, v.29, p.353-360, 1996.

WRAY, C.I.M. \&; D AVIES, R.H. Guidelines on detection and monitoring of Salmonellainfected poultry flockswith particular reference of S. Enteritidis. Bulletin of the W orld H ealth Organization, v.173, p.1-48, 1994.

Yuno,M.M.I.;T erzolo,H.R.;F ernandes, H.D.;M alena, R.C.; Autuna, M.E.Evaluation of selectiveculturemediafor isolation of Salmonellafrom poultry. RevistaA rgentina de M icrobiologia, v.18, p.57-69, 1995.

Recebido em 6/ 4/ 06

A ceito em 15/ 8/ 06 